\title{
Voting and Attitudes Along the Red Rural-Blue Urban Continuum
}

Kenneth M. Johnson and Dante J. Scala

I $\mathrm{n}$ attempting to explain the unexpected results of the 2016 presidential election, political analysts have emphasized the differences in party affiliation and social attitudes between Republican (conservative) rural America and Democratic (liberal) urban America. Yet, our study of the 2018 congressional election demonstrates that voting patterns and political attitudes vary across the spectrum of urban and rural areas in the United States. ${ }^{1}$ Rural America is not a monolith, nor is urban America. The rural-urban gradient is better represented by a continuum than a dichotomy. ${ }^{2}$ At one pole of the continuum are large, densely settled urban cores, where Democrats have consistently been the most successful. At the other end are rural counties far from a metropolitan area, without large towns, where Republican candidates command their greatest support.

This study of the 2018 congressional midterms confirms our earlier analysis of the 2016 presidential election and demonstrates how voting patterns and political attitudes vary across the spectrum of urban and rural areas. ${ }^{3}$ Part of the explanation for these differential voting patterns may well rest in the substantial variation from one end of the continuum to the other in social and political attitudes. Just as we found a rural-urban continuum for voting, we also find here that voters at the furthest rural end of the continuum express social and political attitudes far different from their counterparts in the largest urban cores, with suburban residents and those in rural counties with large towns falling in between. A major point of discontinuity along the continuum is evident in the suburban counties of smaller metropolitan areas. Residents of these areas tend to vote more like their rural counterparts and share their social and political attitudes.

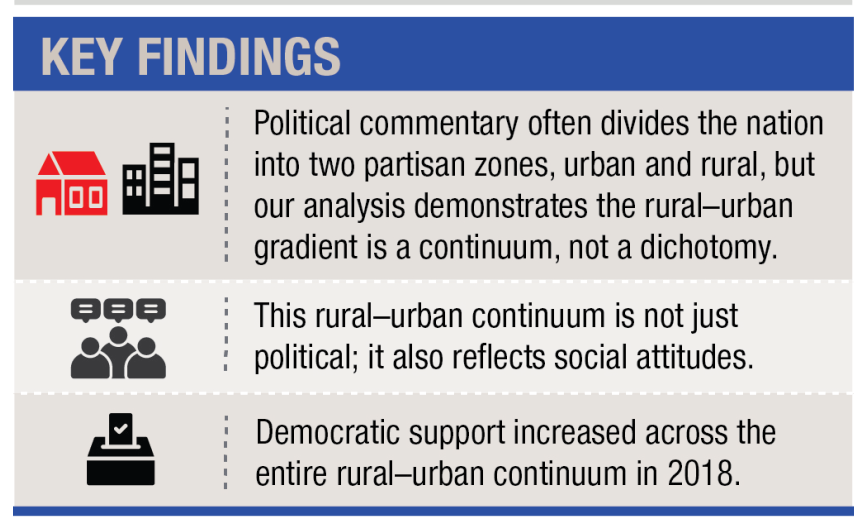

\section{Congressional Voting Patterns Along the Rural-Urban Continuum}

The rural-urban continuum delineated a clear and consistent voting pattern in 2018 contests for the House of Representatives (Figure 1). Democrats received 67.3 percent of the vote in 2018 in the counties containing the large cities at the core (Large Core; see Box 1 on page 4) of metropolitan areas of a million or more. Democratic support was more modest but still a majority of the vote in suburban counties of these large metropolitan areas (Large Suburb) and in the core counties of smaller metropolitan areas (Small Suburb). Together, these three groups of counties include 90.1 million (79 percent) of the 113.4 million votes cast in House races in 2018. Democrats suffered steep drop-offs in support further toward the rural end of the continuum; in each of the four nonmetropolitan categories, Republican candidates consistently received a substantial majority of votes in 2018, and they did particularly well in rural counties that did not include a large town. For example, Democrats received 


\section{FIGURE 1. PERCENT DEMOCRATIC IN 2018 AND 2016 HOUSE ELECTIONS AND 2016 PRESIDENTIAL ELECTION ALONG THE RURAL-URBAN CONTINUUM}

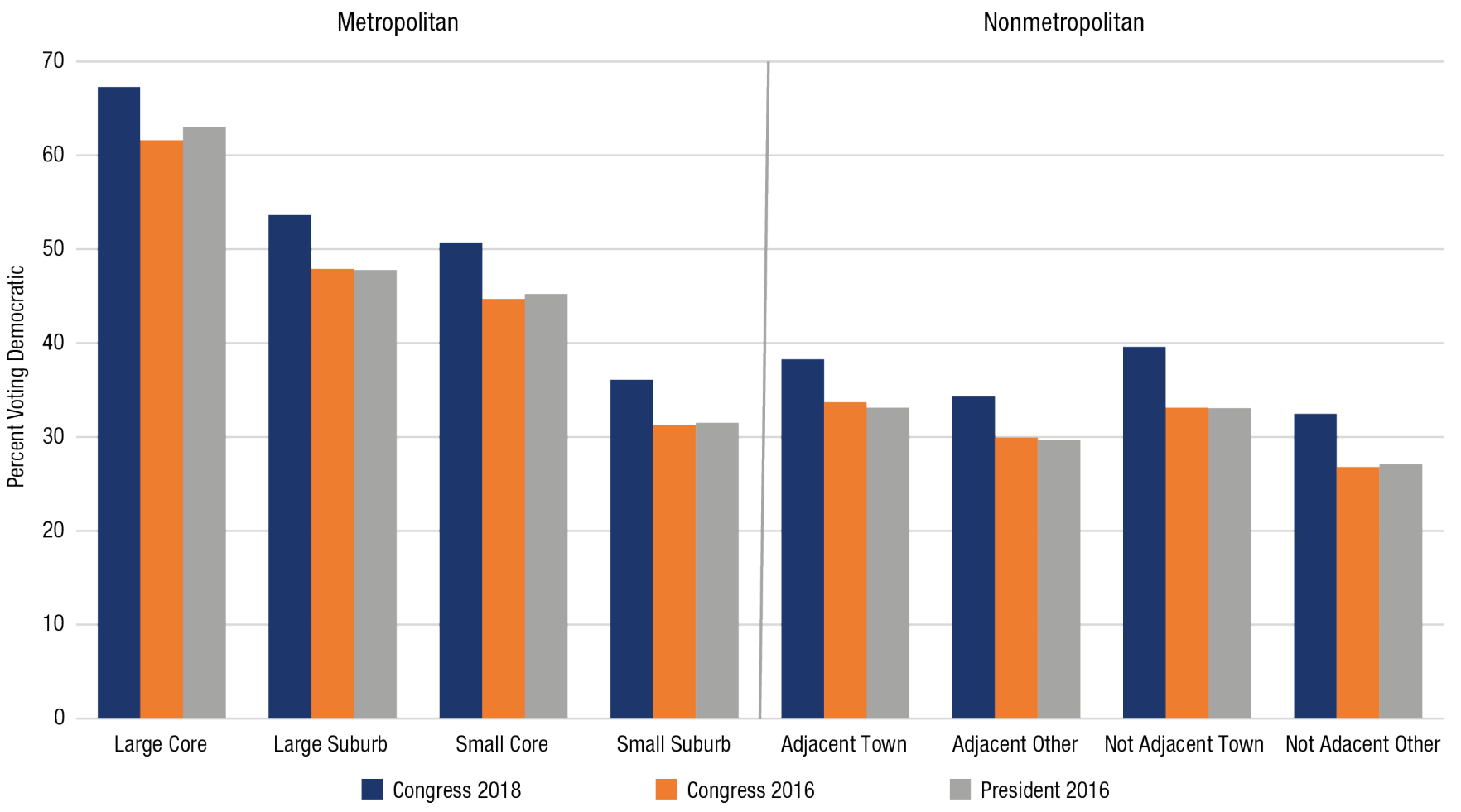

Source: K.M. Johnson and D.J. Scala, Forum 2020

just 32.5 percent of the vote in counties that were not adjacent to a metropolitan area and had no large town (Not Adjacent Other). Republicans also enjoyed strong showings in nonmetropolitan counties containing a large town as well as in suburban counties of small metropolitan areas, which displayed voting patterns more similar to rural counties than to the other metropolitan counties.

Overall, Democrats received 53.2 percent of the House vote in 2018 compared to 47.5 percent in 2016. Democratic support increased across the entire rural-urban continuum, not just in the traditional strongholds of the party in urban cores. In each of the eight categories along the continuum, the proportion of the vote for Democrats increased by 5 to 6 percentage points.
The 2016 congressional elections mirrored the 2016 presidential results, and the rural-urban gradient is evident at both levels. Democratic support was greatest in large urban cores, diminished in large suburban and smaller urban core counties, and then declined sharply in nonmetropolitan counties, especially those counties without a town as well as suburban counties of small metropolitan areas.

\section{Social Attitudes Along the Rural-Urban Continuum}

Differences in attitudes along the rural-urban continuum may well account for the distinct voting patterns evident above. On the four scales we used-attitudes on race and gender, isolationism, the role of government, and abortion (see the Data and Methods section for more detail)—residents of major metropolitan areas represent one end of the continuum and display attitudes that differ significantly from those who live in other parts of the country (Figure 2). On all four scales, attitudes of residents in the suburbs of large metro areas and in smaller metro cores represent a middle ground, with attitudes near the national average -in other words, less liberal than those of residents in large urban cores, but far less conservative than those of residents of small metro suburbs and nonmetropolitan areas. In rural areas, the presence of a large town in the county tends to moderate attitudes somewhat, and the most conservative views are consistently found among those in counties without a large town. As in the voting data, 


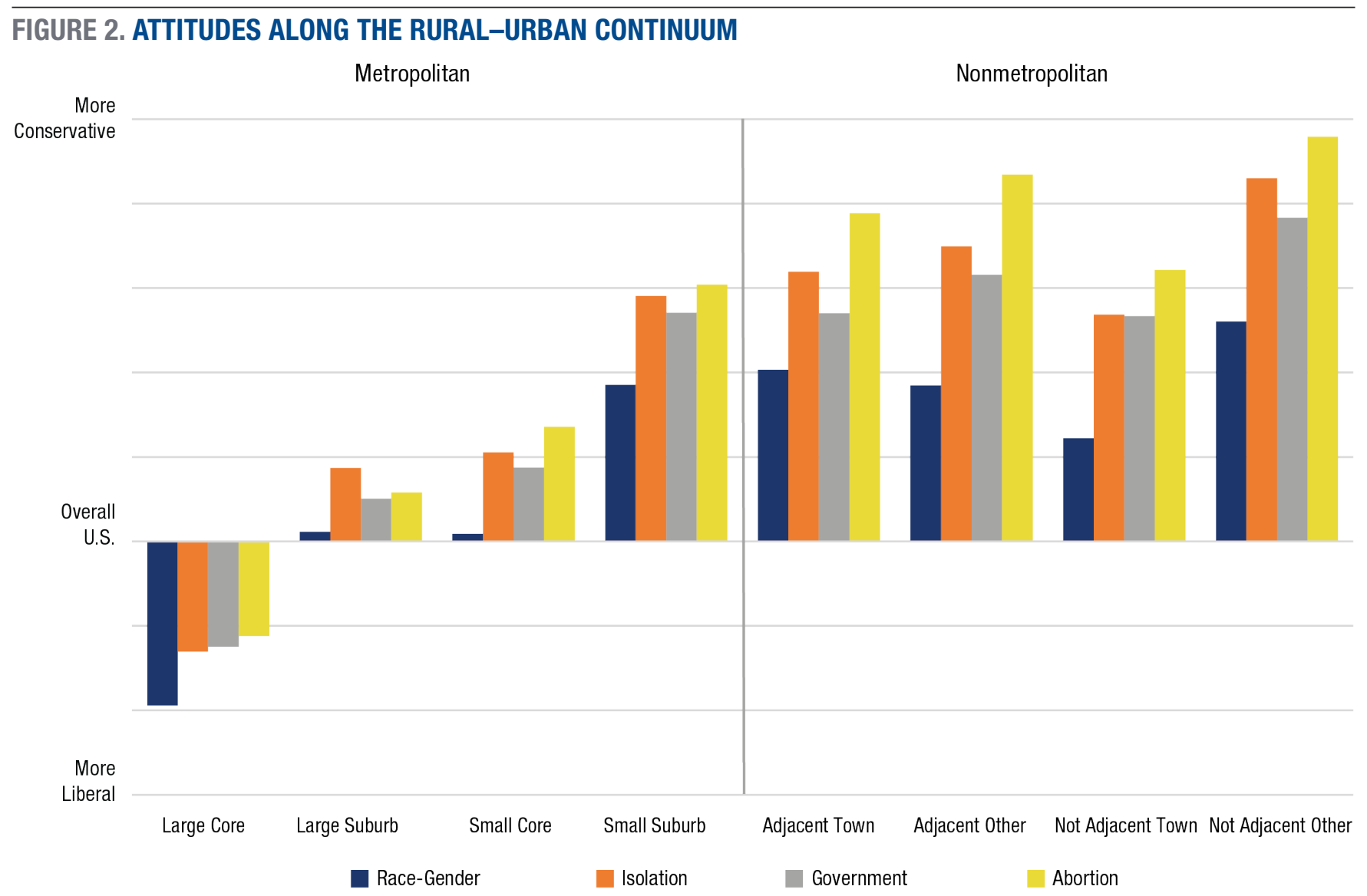

Source: K.M. Johnson and D.J. Scala, Forum 2020

there is an inflection point in the suburbs of small metropolitan areas, where attitudes are more consistent with nonmetropolitan counties containing a town than they are with the other three metropolitan county types.

Though a rural-urban continuum is evident on all four attitude scales, it is the most pronounced as a straight slope in terms of abortion. On this scale, there was a clear and linear urban-rural gradient with a single exception (Not Adjacent Town). Rural residents, especially those in rural counties without a large town, were much more likely to favor restrictions on abortion. Residents of nonmetropolitan counties with a town as well as those residing in small metropolitan suburbs also favored more restrictions on abortions, though these residents were slightly less conservative. Residents of the suburban counties of large metro areas, as well as those in small metropolitan core counties, displayed far more moderate attitudes-close to the national average. In contrast, residents of large metropolitan core counties held views significantly more prochoice than any other group on the urban-rural continuum.

All told, attitudinal data closely mirrored voting data. The remarkable consistency of this gradient across a wide range of opinion items along the rural-urban continuum helps to demonstrate why House election results varied so significantly and so consistently.

\section{Rural-Urban Is a Contin- uum, Not a Dichotomy}

The 2018 midterm results provided good news for Democrats, but they also reflected the same rural-urban continuum evident in the 2016 elections. The language of political polarization often leads observers to divide the United States into two opposing partisan zones, urban and rural. But county-level voting and survey data demonstrate that political differences exist not as a bifurcation but rather along a continuum in both urban and rural areas. And these differences are not simply a matter of partisanship but are displayed across a variety of social and political attitudes. 


\section{Box 1: Defining the Rural-Urban Continuum}

Metropolitan areas include counties containing an urban core with a population of 50,000 or more (central city), along with adjacent counties that are highly integrated with the core county. All other counties are classified as nonmetropolitan. To characterize the rural-urban continuum, we subdivided metropolitan and nonmetropolitan counties into eight categories:

\section{Metropolitan (Urban) Counties}

Large Core-64 counties that include the major city of a metropolitan area containing more than 1 million people in 2010. Most of the counties include both the major city and older suburbs.

Large Suburb-365 noncore counties in metropolitan areas of 1 million or more. They encompass newer suburban areas and the periphery of large metropolitan areas.

Small Core-339 metropolitan counties containing the major city in a metropolitan area of less than 1 million. Most contain both the central city and a large proportion of the suburban population.

Small Suburb-392 noncore counties in metropolitan areas of less than 1 million. These counties tend to contain some suburban areas as well as the sparsely settled urban periphery.

\section{Nonmetropolitan (Rural) Counties}

Adjacent Town-372 counties outside a metropolitan area but contiguous to one, that contained a town with a population of 10,000 to 49,999 in 2010.

Adjacent Other-654 counties outside a metropolitan area but contiguous to one, that did not have a town with a population greater than 10,000 in 2010.

Not Adjacent Town-269 counties that are neither metropolitan nor adjacent to a metropolitan area that contained a town with a population of 10,000 to 49,999 in 2010.

Not Adjacent Other-679 counties that are neither metropolitan nor adjacent to a metropolitan area nor did they have a town with a population greater than 10,000 in 2010 .

For example, on the end of the spectrum with large metropolitan core counties, inhabitants voted Democratic in large majorities in 2018; they were most likely to agree that government should play an important role in solving social problems and that the United States should be fully engaged with the world; they tended to be strongly in favor of women's reproductive rights; and they were the most likely to be concerned about race and gender inequality. On the other end of the spectrum, rural voters, especially those in counties without a large town, mostly voted Republican and were likely to express views quite different than those of metropolitan voters on all four scales.

In the middle of the continuum are the suburbs of large metropolitan areas and small metropolitan core counties, but this oft-described political battlefield is not a single entity but rather a part of this continuum. In the suburbs of metropolitan areas of a million or more, Democrats can count many residents among their supporters. But the outskirts of smaller metro areas, where much of the population is widely dispersed, strongly resemble rural America politically-not just in terms of partisanship but across a variety of social and political attitudes. The continuity of the ruralurban continuum across numerous elections and a broad range of attitudinal items underscores the risks of dichotomizing the country into rural and urban. In the many tightly contested areas where the results of an election may depend on a small fraction of the voters, it is imperative that politicians, the media, and researchers recognize the utility of viewing both rural and urban areas as part of a continuum, not as a dichotomy.

\section{Methods and Data}

We examine political data along the rural-urban continuum using aggregate county voting trends in the 2018 and 2016 congressional elections and the 2016 presidential election. We combined these election results with opinion data to identify attitudes of individuals along the rural-urban continuum. More details of the methods and data used are available in our recent article. ${ }^{4}$

We use counties as the unit of analysis, classifying each county as metropolitan or nonmetropolitan. Metropolitan areas include counties containing an urban core with a population of 50,000 or more (central city), along with 
adjacent counties that are highly integrated with the core county. There are 1,163 metro counties and 1,949 counties classified as nonmetropolitan. We use the terms rural and nonmetropolitan interchangeably here, as we do the terms urban and metropolitan. To characterize the rural-urban continuum, we subdivided the counties into eight categories that represent population concentration and proximity, from the densely settled large cities in metropolitan areas of a million or more to the most remote rural periphery (see Box 1). Because of difficulties with boundary changes in Alaska's boroughs, we excluded respondents from that state.

We obtained election data from Leip's online atlas, ${ }^{5}$ and attitude data are from the 2018 Cooperative Congressional Election Study (CCES), a national stratified sample survey that queried 60,000 respondents ${ }^{6}$ about demographic characteristics and political attitudes. ${ }^{7}$ We classify these respondents based on where their county fits along the ruralurban continuum.

Using a factor analysis of items included on the CCES, we constructed four scales to measure the attitudes of respondents in terms of: (1) perceptions of racism, racial resentment, and gender equality; (2) isolationist sentiments, including support or opposition to immigration, trade and tariffs, energy consumption, and climate change; (3) the role of government in a variety of domestic policy areas, including tax increases, stricter controls on guns, and expansion of government-provided health care; and (4) abortion.

\section{Endnotes}

1. This research summarizes our peerreviewed article, Kenneth M. Johnson and Dante J. Scala, “The RuralUrban Continuum of Polarization: Understanding the Geography of the 2018 Midterms," forthcoming in The Forum (2020).

2. We use the terms rural and nonmetropolitan interchangeably here, as we do the terms urban and metropolitan.

3. Dante J. Scala and Kenneth M. Johnson, "Political Polarization Along the Rural-Urban Continuum? The Geography of the Presidential Vote, 2000-2016," Annals of the American Academy of Political and Social Science; 672, no. 1 (2017): 162-84, http://dx.doi.org.unh.idm. oclc.org/10.1177/0002716217712696; Will Wilkinson, “The Density Divide: Urbanization, Polarization, and Populist Backlash" (Washington, DC: Niskanen Center, 2019), https:// www.niskanencenter.org/the-densitydivide-urbanization-polarization-andpopulist-backlash/.

4. Johnson and Scala, forthcoming.

5. David Leip, “David Leip's Atlas of American Elections," 2020, https:// uselectionatlas.org/.

6. The number of respondents varied from question to question. As a result, our scales were built with fewer than 60,000 respondents. The scales measuring isolationism, role of government, and abortion had between 59,100 and 59,700 respondents. The scales measuring racism, racial resentment, and sexism contained questions asked in the CCES post-election wave, and had 51,600 respondents.

7. Brian Schaffner, Stephen Ansolabehere, and Sam Luks, "CCES Common Content, 2018," 2019, https:// doi.org/10.7910/DVN/ZSBZ7K, Harvard Dataverse, V6, UNF:6:hFVU8vQ/ SLTMUXPgmUw3JQ== [fileUNF].

\section{About the Authors}

Kenneth M. Johnson (ken.johnson@ unh.edu) is senior demographer at the Carsey School of Public Policy, Class of 1940 professor of sociology at the University of New Hampshire, and an Andrew Carnegie fellow.

Dante J. Scala (dante.scala@unh.edu) is professor of political science at the University of New Hampshire and a fellow at the Carsey School of Public Policy.

\section{A cknowledgments}

This brief summarizes the authors' research in K.M. Johnson and D.J. Scala, "The Rural-Urban Continuum of Polarization: Understanding the Geography of the 2018 Midterms, "forthcoming in The Forum (2020). Kenneth Johnson's work was supported by his Andrew Carnegie fellowship. The opinions presented here are those of the authors and do not necessarily reflect the views of the funding organizations. 


\section{University of New Hampshire}

1. Carsey School of Public Policy

The Carsey School of Public Policy at the University of New Hampshire is nationally recognized for its research, policy education, and engagement. The school takes on the pressing issues of the twenty-first century, striving for innovative, responsive, and equitable solutions.

Huddleston Hall • 73 Main Street • Durham, NH 03824

(603) $862-2821$

TTY Users: DIAL 7-1-1 OR 1-800-735-2964 (Relay N.H.)

carsey.unh.edu 